\title{
Yeasts with Fermentative Potential Associated with Fruits of Camu-Camu (Myrciaria dubia, Kunth) from North of Brazilian Amazon
}

\author{
Ítalo Thiago Silveira Rocha Matos $\mathbb{D}^{1},{ }^{1}$ Vanderly Andrade de Souza $\mathbb{D}^{\mathrm{D}},{ }^{2}$ \\ Giovana do Rosário D'Angelo $\mathbb{D}^{1},{ }^{1}$ Spartaco Astolfi Filho $\mathbb{D}^{1},{ }^{1}$ Edson Júnior do Carmo $\mathbb{D}^{1}{ }^{1}$ \\ and Marcos José Salgado Vital ${ }^{2}$ \\ ${ }^{1}$ Federal University of Amazonas, Av. Gal Rodrigo Otávio, 3000, Campus Universitário, Setor Sul, Manaus, AM, \\ 69077-000, Brazil \\ ${ }^{2}$ Federal University of Roraima, Av. Ene Garcez, 2413, Aeroporto, Boa Vista, RR 69310-000, Brazil
}

Correspondence should be addressed to Ítalo Thiago Silveira Rocha Matos; italo_matos@ufam.edu.br

Received 9 March 2021; Revised 25 August 2021; Accepted 5 November 2021; Published 3 December 2021

Academic Editor: Argyro Bekatorou

Copyright (C) 2021 Ítalo Thiago Silveira Rocha Matos et al. This is an open access article distributed under the Creative Commons Attribution License, which permits unrestricted use, distribution, and reproduction in any medium, provided the original work is properly cited.

\begin{abstract}
Considering the high biotechnological potential of yeasts associated to edible fruits, a screening for these microorganisms, capable of alcoholic fermentation, was performed in ripe fruits of camu-camu (Myrciaria dubia, Kunth). The fruits were collected from north of Brazilian Amazon, in the floodplain of the Cauamé River. Yeasts were isolated, and fermentation capability was evaluated using Durham tubes. Quantitative assays were performed to calculate ethanol yield $\left(\mathrm{g} \mathrm{g}^{-1}\right)$, specific growth rate $\left(\mathrm{h}^{-1}\right)$, and ethanol productivity $\left(\mathrm{g} \mathrm{L}^{-1} \cdot \mathrm{h}^{-1}\right)$. Taxonomic identification was performed by ribosomal gene nucleotide sequence analysis by alignment using BLASTN. A total of fifteen yeast colonies were isolated, and three of them presented promising ability to ferment glucose to ethanol. These isolates were identified as Candida orthopsilosis, Pichia kudriavzevii, and Meyerozyma caribbica. When cultured in broth containing $180 \mathrm{~g} \cdot \mathrm{L}^{-1}$ of glucose, $M$. caribbica CC003 reached 91.7 percent of the maximum theoretical ethanol concentration $\left(84.4 \mathrm{~g} \cdot \mathrm{L}^{-1}\right)$, presenting an ethanol yield and productivity of $0.4688 \mathrm{~g} \cdot \mathrm{g}^{-1}$ and $0.781 \mathrm{~g} \cdot \mathrm{L}^{-1} \cdot \mathrm{h}^{-1}$, respectively. These results indicate a promising potential of this isolate for bioprocess applications. This paper is a rare report of $C$. orthopsilosis with endophytic habit because most of the references indicate it as a human pathogen. Besides this, $M$. caribbica is a promising fermenter for alcoholic beverages due to its osmotolerance and high ethanol yield. This is the first paper reporting endophytic yeasts associated with fruits of Myrciaria dubia.
\end{abstract}

\section{Introduction}

Yeasts are microorganisms from the fungi kingdom that present asexual reproduction by fission or budding and with sexual reproductive structure not presenting fruiting bodies [1]. There are more than 2500 species described and recognized in the specialized literature [2], but despite this number, there are only about 80 species used in bioprocesses in the laboratory scale and a few more than twelve used in industrial processes [3].
Amazon is the greatest tropical rainforest of the world, containing about 220 edible fruit species [4], including camucamu (Myrciaria dubia, Myrtaceae, Myrtales, Magnoliopsida, Magnoliophyta, Plantae). Fruits are potentially the natural habitat to a great variety of microorganisms because of their abundance of sugars and water, being favorable to proliferation of yeasts, mainly those capable of alcoholic fermentation. Despite all these potentials, research studies about yeast communities associated to Amazonian fruits are scarce, some of those dating more than two decades ago [5]. 
Myrciaria dubia has attracted a lot of attention because of its remarkable quantity of bioactive compounds [6]. Especially because of their antioxidant activity, their fruits have been used for functional food production, including an artisanal beer with high ascorbic acid concentration [7]. Besides this, there are no specific studies published about the microbiota associated with their leaves, roots, or fruits. The elucidation about yeasts associated to this plant may result in new strains with applicability to both biofuel and food industries.

In this context, for taxonomic purposes and for biotechnological applications, sampling efforts are a necessary approach. The aim of this work was to identify yeasts isolated from fruits of Myrciaria dubia capable of performing alcoholic fermentation and evaluate some kinetic parameters along the fermentative process.

\section{Materials and Methods}

2.1. Sampling and Yeast Isolation. Ripe fruits of M. dubia were collected manually from the bushes (Cauamé River floodplain, $2^{\circ} 51^{\prime} 54.79^{\prime \prime} \mathrm{N}, 60^{\circ} 39^{\prime} 44.19^{\prime \prime} \mathrm{W}$ ) and maintained under refrigeration $\left(4^{\circ} \mathrm{C} \pm 2\right)$ until processing (about $2 \mathrm{~h}$ ). The fruits were washed in fresh water to remove macroparticles, immersed in sodium hypochlorite solution $(1 \% \mathrm{v} /$ v) for $1 \mathrm{~min}$ and ethanol $70 \%$ for $1 \mathrm{~min}$, and, finally, washed in sterilized distilled water for $2 \mathrm{~min}$. After superficial decontamination, fruits were stored in a sterilized vessel at room temperature until developing an aroma resembling bread or alcoholic beverage at about 7 days (samples processed on the first day after they were collected did not present colony growth). Then, their peels were removed, and the mesocarps were mashed in sterilized distilled water (1: $10 \mathrm{w} / \mathrm{v})$.

Aliquots of $100 \mu \mathrm{L}$ were spread in plates containing GYMP agar (glucose $10 \mathrm{~g} \cdot \mathrm{L}^{-1}$, yeast extract $3 \mathrm{~g} \cdot \mathrm{L}^{-1}$, malt extract $3 \mathrm{~g} \cdot \mathrm{L}^{-1}$, peptone $5 \mathrm{~g} \cdot \mathrm{L}^{-1}$, agar $20 \mathrm{~g} \cdot \mathrm{L}^{-1}$, and $\mathrm{pH} 5.0$ ), and the plates were incubated at $28^{\circ} \mathrm{C}$ until $48 \mathrm{~h}$. Colonies presenting typical yeast's morphology were isolated and stored in sterilized mineral oil.

2.2. Fermentation Assays. A qualitative fermentation test was performed, evaluating the capability of the isolates to ferment glucose, D-xylose, sucrose, and maltose. A loopful of each isolate was inoculated in tubes containing liquid media composed of the respective sugar $\left(40 \mathrm{~g} \cdot \mathrm{L}^{-1}\right)$ and yeast extract $\left(10 \mathrm{~g} \cdot \mathrm{L}^{-1}\right)$. The tubes were incubated until 14 days at $28^{\circ} \mathrm{C}$ and evaluated every $24 \mathrm{~h}$ to identify fermentation, evidenced by gas retention into Durham tubes [8]. In these assays, the final cell concentration was equivalent to 1.0 in the McFarland scale, and they were performed in triplicate.

Some isolates were selected for a quantitative test, besides evaluating their osmotolerance, according to their ability to grow at high osmotic pressure $(\pi=24.68 \mathrm{~atm})$, according to Jimoh et al. [9]. The isolates were inoculated in $250 \mathrm{~mL}$ Erlenmeyer flasks containing $100 \mathrm{~mL}$ of broth $(\mathrm{pH}$ $5.0)$ composed of glucose $\left(180 \mathrm{~g} \cdot \mathrm{L}^{-1}\right)$ and yeast extract $\left(10 \mathrm{~g} \cdot \mathrm{L}^{-1}\right)$ and incubated at $28^{\circ} \mathrm{C}$ and $120 \mathrm{rpm}$ until $120 \mathrm{~h}$.
TABLE 1: Fermentative capability of yeasts isolated from Myrciaria dubia.

\begin{tabular}{lcccc}
\hline \multirow{2}{*}{ Isolate } & \multicolumn{5}{c}{ Sugars } \\
& Glucose & Sucrose & Maltose & D-xylose \\
\hline CC001 & ++ & - & - & - \\
CC002 & ++ & - & - & - \\
CC003 & +++ & - & - & - \\
CC004 & + & + & - & - \\
CC005 & + & + & - & - \\
CC006 & +++ & - & - & - \\
CC007 & +++ & - & - & - \\
CC008 & - & - & - & - \\
CC009 & - & - & - & - \\
CC010 & - & - & - & - \\
CC011 & - & - & - & - \\
CC012 & - & - & - & - \\
CC013 & - & - & - & - \\
CC014 & - & - & - & - \\
CC015 & + & +++ & - & - \\
\hline
\end{tabular}

$(+++)$ : positive results in $48 \mathrm{~h} ;(++)$ : positive results in $72 \mathrm{~h} ;(+)$ : positive results in $96 \mathrm{~h}$ or more; (-): no fermentation evidence along 14 days.

Fermentation was monitored every $12 \mathrm{~h}$ by measuring the mass of $\mathrm{CO}_{2}$ released, according to Dijck et al. [10]. Total inoculum was about $5 \mathrm{~g} \cdot \mathrm{L}^{-1}$ (dry weight), and kinetic parameters were evaluated according to Section 2.4.

2.3. Taxonomic Identification. Yeasts with fermentative capability were identified using the nucleotide sequences of D1/D2 26S rDNA genes. Genomic DNA was extracted according to the previous description [11] and amplified by PCR techniques using primers NL1 and NL4 [12]. The amplicons were used for the sequencing reaction using the BigDye kit (Applied Biosystems ${ }^{\circledR}$ ), and nucleotide sequences were obtained using a 3500 automatic genetic analyzer (Applied Biosystems ${ }^{\oplus}$ ). The sequences were compared to the GenBank database by alignment using the online tool BLASTN (https://blast.ncbi.nlm.nih.gov/Blast.cgi).

2.4. Kinetic Parameters and Analytical Methods. Ethanol concentration $\left([\mathrm{EtOH}], g \cdot \mathrm{L}^{-1}\right)$ along fermentation was determined by stoichiometric calculation, as previously described [10]. Specific growth rate $\left(\mu_{\mathrm{MAX}}, \mathrm{h}^{-1}\right)$ was calculated by the equation $\ln [\mathrm{EtOH}]_{n} /[\mathrm{EtOH}]_{i}=\mu_{\mathrm{MAX}} * t \pm b$, where $[\mathrm{EtOH}]_{n} /[\mathrm{EtOH}]_{i}$ is the relation between the current and initial ethanol concentration along the log phase and $t$ is the time in hours, according to Duarte et al. [13].

Ethanol yield $\left(\mathrm{Y}_{\mathrm{EtOH}}, g \cdot g^{-1}\right)$ was calculated by the relation between the mass of ethanol produced and mass of glucose consumed. Ethanol productivity $\left(\mathrm{Q}_{\mathrm{EtOH}}\right.$, $g \cdot \mathrm{L}^{-1} \cdot \mathrm{h}^{-1}$ ) was calculated by the relation between the final ethanol concentration and total time of fermentation before the stationary phase. Total reducing sugar concentration ([TRS], $g \cdot \mathrm{L}^{-1}$ ) was determined using the dinitrosalicylic acid method (DNS). Aliquots of $20 \mu \mathrm{L}$ of the samples (diluted in distilled water, $1: 10 \mathrm{v} / \mathrm{v}$ ) were mixed with $180 \mu \mathrm{L}$ of distilled water and $300 \mu \mathrm{L}$ of DNS solution. After 5 min of boiling, $1500 \mu \mathrm{L}$ of distilled water was added, and the 
TABLE 2: Taxonomic identification of yeasts isolated from Myrciaria dubia.

\begin{tabular}{lccc}
\hline Isolate & Species & $\begin{array}{c}\text { High similarity } \\
(\%)\end{array}$ & $\begin{array}{c}\text { Strains } \\
\text { related }\end{array}$ \\
\hline CC001 & Pichia kudriavzevii & 100 & ATCC 34135 \\
CC002 & Pichia kudriavzevii & 100 & ATCC 34135 \\
CC005 & Candida orthopsilosis & 99.57 & CBS 11337 \\
CC015 & $\begin{array}{c}\text { Candida orthopsilosis } \\
\text { Meyerozyma } \\
\text { CC003 }\end{array}$ & 99.57 & CBS 11337 \\
CC006 & $\begin{array}{c}\text { Meyerozyma } \\
\text { caribbica }\end{array}$ & 99.81 & CBS 9966 \\
\hline
\end{tabular}

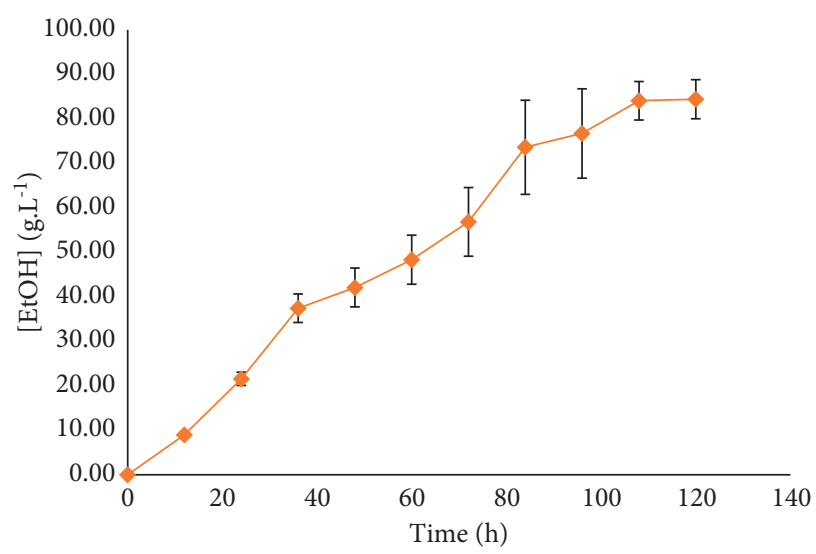

FIGURE 1: Ethanol production by Meyerozyma caribbica CC003 along $120 \mathrm{~h}$ of fermentation. The stationary phase was observed after $108 \mathrm{~h}$. Error bars indicate standard deviation.

absorbance was determined at $540 \mathrm{~nm}$. [TRS] was calculated using the formula obtained from a calibration curve.

\section{Results}

3.1. Isolation and Fermentative Capability. A total of 15 colonies were isolated, being identified with a numeric code preceded by "CC" (due to camu-camu, the vernacular form in Portuguese to Myrciaria dubia). More than a half were capable of fermenting glucose, and some were capable to ferment sucrose. No colonies presented capability to ferment D-xylose and maltose. The results are presented in Table 1.

Due to colony morphology and fermentative profile, some isolates were considered clones: CC001 and CC002; CC003, CC006, and CC007; and CC004, CC005, and CC015. Because of presenting positive results in all tubes of the qualitative assays, CC001, CC003, and CC015 were selected for quantitative fermentation assays.

3.2. Taxonomic Identification. A total of six isolates were identified, and the obtained sequences were deposited in the NCBI database under accession number PRJNA645409. The isolates were identified according to Table 2 .

3.3. Kinetic Parameters and Analytical Methods. In assays with the initial glucose concentration of $180 \mathrm{~g} \cdot \mathrm{L}^{-1}$, Pichia kudriavzevii CC001 and Candida orthopsilosis CC015 presented the final ethanol concentration of $39.94( \pm 2.21)$ and $34.57( \pm 3.42) \mathrm{g} \cdot \mathrm{L}^{-1}$, respectively. These results correspond, respectively, to 43.4 and 37.5 percent of the theoretical maximum; for this reason, they were considered not promising for fermentation applications and not further evaluated for other kinetic parameters.

Meyerozyma caribbica CC003 presented a final ethanol concentration of $84.4( \pm 3.18) \mathrm{g} \cdot \mathrm{L}^{-1}$, corresponding to $91.7 \%$ of the theoretical maximum. Final [TRS] indicated full consumption of glucose, meaning that this isolate is osmotolerant. $\mathrm{Y}_{\mathrm{EtOH}}$ was $0.4688 \mathrm{~g} \cdot \mathrm{g}^{-1}, \mathrm{Q}_{\mathrm{EtOH}}=0.781 \mathrm{~g} \cdot \mathrm{L}^{-1} \cdot \mathrm{h}^{-1}$, and $\mu_{\mathrm{MAX}}=0.025 \mathrm{~h}^{-1}$. The ethanol production kinetic by M. caribbica CC003 is presented in Figure 1.

\section{Discussion}

The occurrence of $P$. kudriavzevii was reported to be associated with blossom and ripped fruits of apple, pear, and plum in southwest Slovakia [14]. Its association with natural fermentation of ripped pulp fruits was described when microorganisms associated with Ziziphus mauritiana were screened [15]. Robs et al. [16] reported its occurrence associated with rotten fruits in a pineapple plantation in Rio de Janeiro, Brazil. Furthermore, the occurrence of this yeast was reported in association with rotten fruits of Byrsonima sp. [5], a common fruiting plant around the collecting site of this work.

P. kudriavzevii was also reported in association with natural fermentation of cereal dough in West Africa [17], in Chinese liquor Daqu [18], and as a component of the terroir of North Patagonian winemaking [19]. Together, these facts indicate that P. kudriavzevii is a typical endophytic yeast associated with fruits, including M. dubia, and safe for human consumption.

Most of the reports about C. orthopsilosis in scientific databases are related to human health problems. This species is closely related to C. parapsilosis, commonly described as a commensal in human skin and pathogenic yeast, capable to develop human tissue invasion and damage [20]. Scarce reports describe this yeast associated to fruits of Opuntia stricta [21] and tomatoes [22].

Its occurrence was described in natural fermentation of cotton seeds and rice beverage produced by Brazilian Amerindians [23]. This isolate could belong to the C. parapsilosis species complex, and further approach about its exact identification must be evaluated using other molecular markers. Because of the possibility of being a pathogenic isolate, its uses in industrial processes should be avoided until confirmative analysis for taxonomic identification and safe use.

Firstly, Meyerozyma caribbica was described as Pichia caribbica, distinguished from P. guilliermondii [24]. The type strain was isolated from sugar cane in Cuba, which explains its name "caribbica." Further analysis repositioned it in a new genus, currently named Meyerozyma [25].

Its occurrence was reported in association with rhizosphere in high salinity soil in South Korea [26] and in corn-derived starch granules in Illinois, USA [1], and it was associated with different insects of the order Diptera [27]. $M$. caribbica was also reported as a prevalent species in the 
natural wet fermentation of coffee fruits and beans in Brazil [28] and in Mangifera indica fruits in Mexico [29]. These facts indicate that this species is worldwide distributed and presents a cosmopolitan habit.

The biotechnological applications of $M$. caribbica include its use as oleaginous yeast for biodiesel production [30] and as a biological control agent against Colletotrichum gloeosporioides in fruits of Mangifera indica [31]. The yeast powder presented effectiveness even after 6 months of storage. $M$. caribbica did not induce any animal toxicity or obvious cytotoxic activity [32]. It was used in a mixed inoculum with Saccharomyces cerevisiae to produce cachaça (sugar cane spirit) because of its ability to produce ethyl acetate and other compounds resembling the fruit's aroma [33]. Together, with its natural occurrence associated with fruits, it indicates that $M$. caribbica is safe to the food industry.

The results of qualitative fermentation tests corroborate as predicted by the literature, with most of the yeasts belonging to ascomycetous groups and capable of fermenting glucose [5]. The final ethanol concentration obtained by P. kudriavzevii CC001 was similar to that observed for different wild-type strains isolated by Chamnipa et al. [34]. The low yield observed can be explained by the relatively low incubation temperature as the highest yields were obtained when temperatures over $40^{\circ} \mathrm{C}$ were used $[35,36]$. This possibility must be reevaluated in a further research project.

Ethanol production by $C$. orthopsilosis was similar to that obtained by Chamnipa et al. [34] when using a wild-type strain. Low yield in alcoholic fermentation seems to be a common feature for this species.

The percentage of the maximum theoretical yield observed for M. caribbica CC003 (91.7\%) is higher than the yield (84.9\%) obtained by Sukpipat et al. [37] when using a strain of $M$. caribbica for fermenting glucose $\left(50 \mathrm{~g} \cdot \mathrm{L}^{-1}\right)$ to ethanol. The values of $\mathrm{Y}_{\mathrm{EtOH}}$ observed here were similar to those obtained when $S$. cerevisiae and P. kudriavzevii were used to produce ethanol using glucose as the substrate [38] and when $M$. caribbica was used to produce a new sweet sorghum distilled beverage [39]. Furthermore, $\mathrm{Y}_{\mathrm{EtOH}}$ by CC003 is more than four times higher than that obtained when a wild-type strain of $M$. caribbica, isolated from Vietnam, was used to ferment glucose to ethanol [40].

Its ability to grow in moderate to high glucose concentrations and also present high ethanol yield indicates osmotolerance and suitability of this strain to ferment high original gravity brewing wort [41]. These results indicate that $M$. caribbica CC003 is a promising fermenter for application to both food and alcoholic beverage industries.

The values of $\mathrm{Q}_{\mathrm{EtOH}}$ and $\mu_{\mathrm{MAX}}$ were lower than all the compared references, indicating slow speed of fermentation probably due to relatively small initial inoculum. Temperature and initial inoculum are factors that need to be adjusted in further works.

\section{Conclusions}

This paper is a rare report of the endophytic occurrence of C. orthopsilosis as most of the references indicate this species as a human pathogen. There are scarce papers reporting the natural occurrence associated with fruits and other environmental samples. Other molecular markers must be evaluated to establish the difference between safe and pathogenic lineages of this species. Besides presenting high ethanol yield, Meyerozyma caribbica CC003 also presents tolerance to elevated amounts of glucose and ethanol. Therefore, it is a promising fermenter for alcoholic beverage production. The subsequent efforts will focus on the production of an alcoholic beverage using M. caribbica CC003, evaluating its chemistry profile, nutritional properties, and organoleptic characteristics.

\section{Data Availability}

All the data generated or analysed during this study are included within this published article.

\section{Ethical Approval}

Not applicable.

\section{Consent}

Not applicable.

\section{Conflicts of Interest}

The authors declare that they have no conflicts of interest.

\section{Acknowledgments}

Special thanks go to Universidade Federal de Roraima, PRONAT, because of the materials for assays and Universidade Federal do Amazonas because of the license for training. This research was supported by Conselho Nacional de Desenvolvimento Científico e Tecnológico (CNPq), Coordenação de Aperfeiçoamento de Pessoal de Nível Superior (CAPES), and Fundação de Amparo a Pesquisa do Estado do Amazonas (FAPEAM).

\section{References}

[1] C. P. Kurtzman, J. W. Fell, and T. Boekhout, The Yeasts, a Taxonomic Study, Elservier, vol. 1, pp. 3-5, , Oxford, UK, 2011.

[2] S. H. Mohd Azhar, R. Abdulla, S. A. Jambo et al., "Yeasts in sustainable bioethanol production: a review," Biochemistry and Biophysics Reports, vol. 10, pp. 52-61, 2017.

[3] M. Türker, "Yeast biotechnology: diversity and application," in Proceedings of the 27th VH Yeast Conference. Advances in Science and Industrial Productions of Baker's Yeast, İstanbul, Turkey, April 2014.

[4] J. E. U. Carvalho, "Frutas da Amazônia na era das novas culturas," in Proceedings of the Anais do Congresso Brasileiro de Recursos Genéticos, DF: Sociedade Brasileira de Recursos Genéticos, Belém, PA. Brasília, September 2012.

[5] P. F. Ganter, P. B. Morais, and C. A. Rosa, Yeasts in Natural Ecosystems: Diversity, P. Buzzini and Y. A. Lachance MA, Eds., Springer, Cham, Springer, 2017 Yeasts in Cacti and Tropical Fruit.

[6] L. Azevedo, P. F. de Araujo Ribeiro, J. A. de Carvalho Oliveira et al., "Camu-camu (Myrciaria dubia) from commercial cultivation has higher levels of bioactive compounds than 
native cultivation (Amazon forest) and presents antimutagenic effects in vivo," Journal of the Science of Food and Agriculture, vol. 99, no. 2, pp. 624-631, 2019.

[7] C. É. M. Pimentel, I. L. Santiago, S. K. M. S. Oliveira, and R. L. Serudo, "Production of artisan beer with added ascorbic acid from amazonic fruit," Brazilian Journal of Development, vol. 5, no. 10, pp. 18553-18560, 2019.

[8] J. A. Barnett, R. W. Payne, and D. Yarrow, Yeasts: Characteristics and Identification, pp. 3-1139, Cambridge University Press, Cambridge, UK, 2000.

[9] S. O. Jimoh, A. J. Baba, A. S. Ado, and C. M. Z. Wng, "Osmotolerance and fermentative pattern of brewer's yeast," World Journal of Life Sciences and Medical Research, vol. 2, no. 2, pp. 59-64, 2012.

[10] P. V. Dijck, P. Mal, M. Versele et al., “A baker's yeast mutant (fil1) with a specific, partially inactivating mutation in adenylate cyclase maintains a high stress resistance during active fermentation and growth," Journal of Molecular Microbiology and Biotechnology, vol. 2, no. 4, pp. 521-530, 2000.

[11] L. H. Rosa, A. B. M. Vaz, R. B. Caligiorne, S. Campolina, and C. A. Rosa, "Endophytic fungi associated with the antarctic grass Deschampsia antarctica desv. (Poaceae)," Polar Biology, vol. 32, no. 2, pp. 161-167, 2009.

[12] M. Lachance, H. Daniel, W. Meyer, G. Prasad, S. Gautam, and K. Boundymills, "The D1/D2 domain of the large subunit rDNA of the yeast species is unusually polymorphic," FEMS Yeast Research, vol. 4, no. 3, pp. 253-258, 2003.

[13] L. C. Duarte, F. Carvalheiro, S. Lopes, I. Neves, and F. M. Gírio, "Yeast biomass production in brewery's spent grains hemicellulosic hydrolyzate," Applied Biochemistry and Biotechnology, vol. 148, no. 1-3, pp. 119-129, 2008.

[14] R. Vadkertiová, J. Molnárová, D. Vránová, and E. Sláviková, "Yeasts and yeast-like organisms associated with fruits and blossoms of different fruit trees," Canadian Journal of Microbiology, vol. 58, no. 12, pp. 1344-1352, 2012.

[15] L. K. Nyanga, M. J. R. Nout, T. H. Gadaga, B. Theelen, T. Boekhout, and M. H. Zwietering, "Yeasts and lactic acid bacteria microbiota form masau (Ziziphus mauritiana) fruits and their fermented fruit pulp in Zimbabwe," International Journal of Food Microbiology, vol. 120, pp. 159-166, 2007.

[16] P. G. Robbs, A. N. Hagler, and L. C. Mendonça-Hagler, "Yeasts associated with a pineapple plantation," Yeast, vol. 5, pp. 485-489, 1989.

[17] M. Houngbédji, P. Johansen, S. W. Padonou et al., "Occurrence of lactic acid bacteria and yeasts at species and strain level during spontaneous fermentation of mawè, a cereal dough produced in west Africa," Food Microbiology, vol. 76, pp. 267-278, 2018.

[18] D. Xu, Y. Yin, B. Ali, Y. Zhang, L. Guo, and X. Xu, "Isolation of yeast strains from Chinese liquor daqu and its use in the wheat sourdough bread making," Food Bioscience, vol. 31, Article ID 100443, 2019.

[19] S. M. del Mónaco, M. E. Rodríguez, and C. A. Lopes, "Pichia kudriavzevii as a representative yeast of north patagonian winemaking terroir," International Journal of Food Microbiology, vol. 230, pp. 31-39, 2016.

[20] A. Gácser, W. Schäfer, J. S. Nosanchuk, S. Salomon, and J. D. Nosanchuk, "Virulence of Candida parapsilosis, Candida orthopsilosis, and Candida metapsilosis in reconstituted human tissue models," Fungal Genetics and Biology, vol. 44, no. 12, pp. 1336-1341, 2007.

[21] C. P. Kurtzman, J. W. Fell, and T. Boekhout, The yeasts, a taxonomic study, vol. 2, pp. 293-1331, Elservier, Oxford, UK, 2011.
[22] D. Robl, S. S. Thimoteo, G. C. C. F. d. Souza et al., "Occurrence of Candida orthopsilosis in brazilian tomato fruits (Lycopersicum esculentum Mill.)," Brazilian Journal of Microbiology, vol. 45, no. 1, pp. 105-109, 2014.

[23] C. L. Ramos, E. G. De Almeida, A. L. Freire, and R. Freitas Schwan, "Diversity of bacteria and yeast in the naturally fermented cotton seed and rice beverage produced by brazilian amerindians," Food Microbiology, vol. 28, no. 7, pp. 1380-1386, 2011.

[24] A. Vaughanmartini, C. Kurtzman, S. Meyer, and E. Oneill, "Two new species in the Pichia guilliermondii clade: Pichia caribbica sp. nov., the ascosporic state of Candida fermentati, and Candida carpophila comb. nov," FEMS Yeast Research, vol. 5, no. 4-5, pp. 463-469, 2005.

[25] C. P. Kurtzman and M. Suzuki, "Phylogenetic analysis of ascomycete yeasts that form coenzyme Q-9 and the proposal of the new genera Babjeviella, Meyerozyma, Millerozyma, Priceomyces, and Scheffersomyces," Mycoscience, vol. 51, no. 1, pp. 2-14, 2010.

[26] J.-S. Kim, J.-H. Baek, N.-H. Park, and C. Kim, "Complete genome sequence of halophilic yeast Meyerozyma caribbica MG20W isolated from rhizosphere soil," Genome Announcements, vol. 3, no. 2, Article ID e00127-15, 2015.

[27] L. De Marco, S. Epis, A. Capone et al., "The genomes of four Meyerozyma caribbica isolates and novel insights into the Meyerozyma guilliermondii species complex," G3.vol. 8, no. 3, pp. 755-759, 2018.

[28] S. R. Evangelista, M. G. d. C. P. Miguel, C. F. Silva, A. C. M. Pinheiro, and R. F. Schwan, "Microbiological diversity associated with the spontaneous wet method of coffee fermentation," International Journal of Food Microbiology, vol. 210, pp. 102-112, 2015.

[29] P. U. Bautista-Rosales, R. Servín-Villegas, M. CalderónSantoyo, and J. A. Ragazzo Sánchez, Control Biológico de Colletotrichum sp. Utilizando Levaduras Antagonistas Nativas del Mango, E. Aguilar-Garnica, M. J. Beltrán-García, D. OrtizMendoza, J. A. Rosas-Jiménez, and J. L. Zavala-Aguirre, Eds., , Universidad Autónoma de Guadalajara, AC, Zapopan, Jalisco, México, 2011pp. 1-10, 3er Congreso Internacional de Biología, Química y Agronomía.

[30] H. Chebbi, D. Leiva-Candia, M. Carmona-Cabello, A. Jaouani, and M. P. Dorado, "Biodiesel production from microbial oil provided by oleaginous yeasts from olive oil mill wastewater growing on industrial glycerol," Industrial Crops and Products, vol. 139, Article ID 111535, 2019.

[31] L. Aguirre-Güitrón, M. Calderón-Santoyo, P. U. BautistaRosales, and J. A. Ragazzo-Sánchez, "Application of powder formulation of Meyerozyma caribbica for postharvest control of Colletotrichum gloeosporioides in mango (Mangifera indica L.)," Lebensmittel-Wissenschaft \& Technologie, vol. 113, Article ID 108271, 2019.

[32] I. B. Ocampo-Suarez, Z. López, M. Calderón-Santoyo, J. A. Ragazzo-Sánchez, and P. Knauth, “Are biological control agents, isolated from tropical fruits, harmless to potential consumers?" Food and Chemical Toxicology, vol. 109, pp. 1055-1062, 2017.

[33] J. C. Amorim, R. F. Schwan, and W. F. Duarte, "Sugar cane spirit (cachaça): effects of mixed inoculum of yeasts on the sensory and chemical characteristics," Food Research International, vol. 85, pp. 76-83, 2016.

[34] N. Chamnipa, S. Thanonkeo, P. Klanrit, and P. Thanonkeo, "The potential of the newly isolated thermotolerant yeast Pichia kudriavzevii RZ8-1 for hightemperature ethanol production," Brazilian Journal of Microbiology, vol. 49, no. 2, pp. 378-391, 2018. 
[35] S. S. Dhaliwal, H. S. Oberoi, S. K. Sandhu, D. Nanda, D. Kumar, and S. K. Uppal, "Enhanced ethanol production from sugarcane juice by galactose adaptation of a newly isolated thermotolerant strain of Pichia kudriavzevii," Bioresource Technology, vol. 102, no. 10, pp. 5968-5975, 2011.

[36] P. Pongcharoen, J. Chawneua, and W. Tawong, "High temperature alcoholic fermentation by new thermotolerant yeast strains Pichia kudriavzevii isolated from sugarcane field soil," Agriculture and Natural Resources, vol. 52, no. 6, pp. 511-518, 2018.

[37] W. Sukpipat, H. Komeda, P. Prasertsan, and Y. Asano, "Purification and characterization of xylitol dehydrogenase with L-arabitol dehydrogenase activity from the newly isolated pentose-fermenting yeast Meyerozyma caribbica 5XY2," Journal of Bioscience and Bioengineering, vol. 123, no. 1, pp. 20-27, 2017.

[38] H. X. Phong, P. Klanrit, N. T. P. Dung, M. Yamada, and P. Thanonkeo, "Isolation and characterization of thermotolerant yeasts for the production of second generation bioethanol," Annals of Microbiology, vol. 69, no. 7, pp. 765-776, 2019.

[39] A. C. A. Lopes, Z. Genisheva, J. A. R. Nunes, and W. F. Duarte, "Production and characterization of a new sweet sorghum distilled beverage," Sugar Tech, vol. 21, no. 6, pp. 966-975, 2019.

[40] V. Tolieng, S. Kunthiphun, A. Savarajara, and S. Tanasupawat, "Diversity of yeasts and their ethanol production at high temperature," Journal of Applied Pharmaceutical Science, vol. 8, no. 2, pp. 136-142, 2018.

[41] G. Dragone, S. I. Mussatto, and J. B. Almeida e Silva, "High gravity brewing by continuous process using immobilised yeast: effect of wort original gravity on fermentation performance," Journal of the Institute of Brewing, vol. 113, no. 4, pp. 391-398, 2007. 